\title{
Study on Mixing Technology of Buton Rock Asphalt Modified HMA
}

\author{
Qingqing $\mathrm{Lu}^{1,2}$
1 Tongji University, Key Laboratory of Road and Traffic Engineering of the Ministry of Education, Shanghai, P.R.China
2 Shanghai Road and Bridge(Group) Co.Ltd.,No.36 Guoke Road, Yangpu District, Shanghai, P.R.China

\section{Corresponding author: loo chey@hotmail.com}

Keywords: Buton Rock Asphalt, new mixing sequences, HMA

Abstract. Buton Rock Asphalt, as a natural asphalt modifier, can be easily dissolved in matrix bitumen, which improves high temperature performance water stability performance and anti-aging performance of asphalt mixture greatly, and lead to the simple production process and easy promotion. However dry mixing process is taken into use in practice which means adding aggregates and BRA firstly, and then adding hot matrix bitumen and mineral power. Considering different adhesions of different parts in mixture to bitumen and characteristics of BRA, six kinds of new mixing sequences were tried and air void, high temperature performance, low temperature performance and water stability performance of mixture were compared to propose a kind of sequence which is easy and of which the mixture has better performance than the mixture of common process. In this sequence, aggregates and matrix bitumen are added first, and then BRA and mineral power are added.

\section{Introduction}

Buton rock asphalt (BRA) is oil in a rock crevice deposition changes over millions of years, under the combined effects of temperature, pressure, gas, inorganic catalyst microorganisms and water oxidation and the pitch, therefore it is very easy solute in the base asphalt, the modified asphalt mixing material has the advantages of simple production process characteristics $[1,2]$. At the same time, Buton rock asphalt as modifier, improve the mixture high temperature stability and rut resistance [3], in addition, with the incorporation of Buton rock asphalt, and show that the rock asphalt can significantly improve the ability of anti-rutting, anti-water damage of asphalt mixture and resistance to fatigue. These are the Buton rock asphalt in road engineering is to promote the use of value.

However, our current standard use of natural rock asphalt, asphalt only proposed principles of technical requirements, is lack of specific indexes on design method and mixing process. Meanwhile, although there are a lot of domestic and foreign research on Buton rock asphalt was limited to the conventional design and mixture performance evaluation, and the lack of research on the optimum mixing process. In the production of most of the projects and laboratory, it mainly includes the following two methods: the first is "wet mix", first preparing Buton rock asphalt modified asphalt, refabricating mixture, but Buton rock asphalt because they contained more ash material, so the method often leads to ash settlement and segregation; the second is "dry mix", Buton rock asphalt and mineral aggregate will be mixing together even after adding matrix asphalt $[4,5,6]$, but this method of Buton rock asphalt adding order as determined by the experience, the lack of experimental support.

Therefore, in this paper, we mainly consider Buton rock asphalt adding order. Six kinds of mixing process are applied, and accompany adjusting mixing time, it will be given six kinds of mixing process, and based on void rate for index comparison to achieve the better improvement process of the two. High temperature performance, low temperature performance and water stability performance are carried out, with the void and road performance for index comparison and analysis of the influence of mixing process on the mixture, and recommend optimum mixing process for engineering application. 


\section{Materials and tests program}

\subsection{Material properties, aggregate and gradation}

The binder contains two types, The 70\# matrix asphalt $+3 \%$ Buton rock asphalt, SBS modified asphalt $+3 \%$ Buton rock asphalt to prepare for asphalt mixture, Technique index of Buton rock asphalt and extraction mineral screening results are shown in Table 1 and table 2, aggregates ranges at $0-3 \mathrm{~mm}, 3-5 \mathrm{~mm}, 5-10 \mathrm{~mm}, 10-15 \mathrm{~mm}$, limestone filler as mineral powder, 70\# base asphalt and SBS modified one meet the specification requirements.

Table 1. Several Technical Indexes of BRA.

\begin{tabular}{|c|c|c|}
\hline Performance Indexes & Test Results & Code Requirements \\
\hline Asphalt Content $(\%)$ & 30.7 & -18 \\
\hline Ash Content $(\%)$ & 69.3 & $\geq 1.70$ and $\leq 1.90$ \\
\hline Density $\left(15^{\circ} \mathrm{C}, \mathrm{g} / \mathrm{cm}^{3}\right)$ & 1.75 & $<2.0$ \\
\hline Moisture Content $(\%)$ & $<1.0$ & \\
\hline
\end{tabular}

Table 2. The Screening Result of BRA after Extraction Test.

\begin{tabular}{|c|c|c|c|c|c|c|c|}
\hline $\begin{array}{c}\text { Pore Size } \\
(\mathrm{mm})\end{array}$ & 4.75 & 2.36 & 1.18 & 0.6 & 0.3 & 0.15 & 0.075 \\
\hline $\begin{array}{c}\text { Pass Ratio } \\
(\%)\end{array}$ & 100 & 98.93 & 91.42 & 84.15 & 73.38 & 54.33 & 38.62 \\
\hline
\end{tabular}

Buton rock asphalt differs from other asphalt modifiers, mainly because it contains more "ash material", and similar ore mineral composition. Therefore, with the incorporation of Buton rock asphalt, gradation design should take the Buton rock asphalt ash material into account, the synthetic gradation close the target gradation.

The study of mixture gradation using AC-13, the gradation design results are shown in Table 3, the matrix asphalt and SBS modified asphalt aggregate ratio was $4.8 \%$, different mixing process of material of each mixture, synthetic mineral aggregate gradation and asphalt content are the same.

Table 3. Gradation Design of AC-13.

\begin{tabular}{|c|c|c|c|c|c|c|c|c|c|c|}
\hline $\begin{array}{l}\text { Pore } \\
\text { Size } \\
(\mathrm{mm})\end{array}$ & $\begin{array}{l}\text { Upper } \\
\text { Limit } \\
(\%)\end{array}$ & $\begin{array}{c}\text { Lower } \\
\text { Limit } \\
(\%)\end{array}$ & $\begin{array}{l}\text { Recommended } \\
\text { Value }(\%)\end{array}$ & $\begin{array}{c}10-15 \\
(\%)\end{array}$ & $\begin{array}{l}5-10 \\
(\%)\end{array}$ & $\begin{array}{l}3-5 \\
(\%)\end{array}$ & $\begin{array}{l}0-3 \\
(\%)\end{array}$ & $\begin{array}{c}\text { Mineral } \\
\text { Powder } \\
(\%)\end{array}$ & $\begin{array}{l}\text { Ash } \\
(\%)\end{array}$ & $\begin{array}{l}\text { Composite } \\
\text { Gradation } \\
(\%)\end{array}$ \\
\hline 16 & 100.0 & 100.0 & 100.0 & 100.0 & 100.0 & 100.0 & 100.0 & 100.0 & 100.0 & 100.0 \\
\hline 13.2 & 100.0 & 90.0 & 97.0 & 91.7 & 100.0 & 100.0 & 100.0 & 100.0 & 100.0 & 98.3 \\
\hline 9.5 & 85.0 & 68.0 & 80.0 & 9.0 & 95.7 & 100.0 & 100.0 & 100.0 & 100.0 & 79.9 \\
\hline 4.75 & 68.0 & 38.0 & 48.0 & 0.2 & 12.3 & 96.9 & 99.5 & 100.0 & 100.0 & 47.9 \\
\hline 2.36 & 50.0 & 24.0 & 29.0 & 0.0 & 0.2 & 7.9 & 88.3 & 100.0 & 98.93 & 30.2 \\
\hline 1.18 & 38.0 & 15.0 & 20.0 & 0.0 & 0.0 & 1.3 & 53.9 & 100.0 & 91.42 & 19.7 \\
\hline 0.6 & 28.0 & 10.0 & 16.0 & 0.0 & 0.0 & 0.7 & 34.0 & 97.4 & 84.15 & 14.1 \\
\hline 0.3 & 20.0 & 7.0 & 12.0 & 0.0 & 0.0 & 0.0 & 18.0 & 92.2 & 73.38 & 9.4 \\
\hline 0.15 & 15.0 & 5.0 & 8.0 & 0.0 & 0.0 & 0.0 & 8.5 & 81.5 & 54.33 & 6.4 \\
\hline 0.075 & 8.0 & 4.0 & 5.0 & 0.0 & 0.0 & 0.0 & 4.8 & 73.6 & 38.62 & 5.1 \\
\hline \multicolumn{4}{|c|}{ Content (\%) } & 0.20 & 0.36 & 0.12 & 0.27 & 0.03 & 0.02 & \\
\hline
\end{tabular}

\subsection{The tests design of mixing process of Buton rock asphalt modified asphalt mixture}

In program, control variable method is adopted to ensure indoor test in various temperature stability, control mixing with a total time of constant 240 seconds. Considering Buton rock asphalt containing large amounts of ash material, compared to the aggregate is fine and asphalt with good compatibility, so this study mainly consider "rock asphalt second adding process", the concrete technological design are as follows:

A. aggregate + rock asphalt $60 \mathrm{~s}+$ matrix asphalt or SBS modified asphalt $90 \mathrm{~s}+$ powder $90 \mathrm{~s}$ (conventional dry mixing process);

B. aggregate + matrix asphalt or SBS modified asphalt $90 \mathrm{~s}+$ rock asphalt $60 \mathrm{~s}+$ powder $90 \mathrm{~s}$; 
C. aggregate + matrix asphalt and SBS modified asphalt 90s+ powder 60s+ rock asphalt 60s;

D. aggregate + Half matrix asphalt or SBS modified asphalt 60s+ rock asphalt 30s+ half matrix asphalt or SBS modified asphalt 90s+ powder 60s;

E. aggregate + half of the matrix asphalt or SBS modified asphalt 60s+ half powder 30s+ rock asphalt $60 \mathrm{~s}+$ half of the matrix asphalt or SBS modified asphalt $45 \mathrm{~s}+$ half powder $45 \mathrm{~s}$.

F. aggregate + matrix asphalt $60 \mathrm{~s}$ or SBS one +powder $60 \mathrm{~s}+$ rock asphalt $60 \mathrm{~s}+$ half powder $60 \mathrm{~s}$.

In the hot mix asphalt mixture in the preparation process, with drying $185^{\circ} \mathrm{C}$ mineral powder and rock asphalt normal temperature. Buton rock asphalt modified asphalt, asphalt heating to $155^{\circ} \mathrm{C}$, in $155 \sim 165^{\circ} \mathrm{C}$ under the pot, molding at $150-160^{\circ} \mathrm{C}$; Buton rock asphalt and SBS composite modified SBS modified asphalt heating to $170{ }^{\circ} \mathrm{C}$ or so, in $165 \sim 175{ }^{\circ} \mathrm{C}$ under the pan, modeled at $160 \sim 170{ }^{\circ} \mathrm{C}[7]$.

\section{Different mixing process of mixture void rate comparison}

\subsection{Comparison test results of void fraction}

Performance of the mixture is effected by air void, and the main parameters of the void ratio is chosen as the key comparison index. According to (JTG E20-2011) "highway engineering asphalt and asphalt mixture test procedures in the" [8], the 70\# matrix asphalt $+3 \%$ Buton rock asphalt A F six mixing processes of mixed income material volume index determination, each process at least forming four Marshall specimens, the specific test results are shown in Table 4 shows.

Table 4. Volume Indexes of Matrix Bitumen Modified with BRA.

\begin{tabular}{|c|c|c|c|}
\hline $\begin{array}{c}\text { Mixing } \\
\text { Processes }\end{array}$ & $\begin{array}{c}\text { Average } \\
\text { VV (\%) }\end{array}$ & $\begin{array}{c}\text { Average } \\
\text { VMA (\%) }\end{array}$ & $\begin{array}{c}\text { Average } \\
\text { VFA (\%) }\end{array}$ \\
\hline A & 4.58 & 15.26 & 70.07 \\
\hline B & 3.51 & 14.27 & 75.76 \\
\hline C & 4.66 & 15.33 & 69.65 \\
\hline D & 4.60 & 15.28 & 69.90 \\
\hline E & 4.26 & 14.98 & 71.57 \\
\hline F & 4.59 & 15.27 & 69.95 \\
\hline $\begin{array}{c}\text { Code } \\
\text { Requirements }\end{array}$ & $4-6$ & $\geq 14$ & $65-75$ \\
\hline
\end{tabular}

Considering different types of asphalt, SBS modified asphalt $+3 \%$ Buton rock asphalt of six kinds of mixing process of mixed income material volume index were measured, specific test results are shown in Table 5.

Table 5. Volume Indexes of SBS Modified Bitumen modified with BRA.

\begin{tabular}{|c|c|c|c|}
\hline $\begin{array}{c}\text { Mixing } \\
\text { Processes }\end{array}$ & $\begin{array}{c}\text { Average } \\
\text { VV (\%) }\end{array}$ & $\begin{array}{c}\text { Average } \\
\text { VMA (\%) }\end{array}$ & $\begin{array}{c}\text { Average } \\
\text { VFA (\%) }\end{array}$ \\
\hline A & 5.04 & 15.67 & 67.85 \\
\hline B & 4.32 & 15.03 & 71.38 \\
\hline C & 5.12 & 15.76 & 67.38 \\
\hline D & 5.53 & 16.11 & 65.70 \\
\hline E & 5.14 & 15.76 & 67.42 \\
\hline F & 5.12 & 15.74 & 67.53 \\
\hline $\begin{array}{c}\text { Code } \\
\text { Requirements }\end{array}$ & $4-6$ & $\geq 14$ & $65-75$ \\
\hline
\end{tabular}

\subsection{Results}

From the test results can be concluded that mixing process have a certain impact on Buton rock asphalt change of asphalt mixture void rate.

Table 4 shows, mixing process $\mathrm{B}$ has a more obvious advantages, void ratio from conventional method A, $4.58 \%$ reduced to $3.51 \%$, decreased by $23.36 \%$. On the other hand, as expected, mixing process of $\mathrm{E}$ can also in the same asphalt aggregate ratio get smaller voids rate, compared with the routine method a, from $4.58 \%$ reduced to $4.26 \%$, reduces $6.99 \%$. The other four kinds of mixing process is the difference. 
From Table 5 can be seen, for Buton rock asphalt and SBS composite modified asphalt mixture can get similar conclusion, mixing process B has a more obvious advantages, from $5.04 \%$ of a conventional methods reduce to $4.32 \%$, reducing the $14.29 \%$. The second is the mixing process of $\mathrm{E}$. To further improve the mixing effect of E process, using the method of extended mixing time, $G$ process is put forward:

Aggregate + half of asphalt 60s+ half mineral powder 60s+ rock asphalt $60 \mathrm{~s}+$ half of asphalt $60 \mathrm{~s}$ + half mineral powder 60 s.

In the same way, the volume parameters are obtained: the average void ratio is $4.12 \%$, the average aggregate clearance rate and saturation is $14.86 \%$ and $72.27 \%$. As you can see, after prolonged mixing time, in process of $\mathrm{G}$ void rate decreased compared with $\mathrm{E}$, compared with conventional methods A, reduced by $10.04 \%$, reflected the advantage of the process of $\mathrm{G}$.

In summary, from the void ratio indicators, at present Buton rock modified asphalt mixture of conventional Process A needs to be improved. In order to further verify the performance, this paper chose $\mathrm{B}, \mathrm{G}$ and conventional method $\mathrm{A}$ to test the high temperature performance, low temperature performance and water stability.

\subsection{Comparison of properties of mixture under different preparation methods}

During the performance test, the base asphalt, 70\#, the void of the three mixing processes to obtain the mixture control air void was $4 \%$. Therefore, the first test to determine the A, B, G three mixing processes of optimal asphalt aggregate ratio, respectively, for $5.2 \%, 4.6 \%$ and $4.9 \%$.

High temperature performance on rutting tests, Low temperature performance on Splitting Tensile, and water stability test results on Freeze-thaw Splitting Test results are shown in Table 67 and 8.

Table 6. Rutting Test Results of Mixture Prepared by Three Mixing Processes.

\begin{tabular}{|c|c|c|c|}
\hline Mixing Processes & A & B & G \\
\hline $\begin{array}{c}\text { Dynamic Stability (times/mm- } \\
{ }^{1} \text { ) }\end{array}$ & 3778 & 3958 & 5910 \\
\hline Total Deformation (mm) & 2.975 & 2.798 & 2.602 \\
\hline
\end{tabular}

Table 7. Low Temperature Splitting Test Results of Mixture Prepared by Three Mixing Processes.

\begin{tabular}{|c|c|c|c|}
\hline Mixing Processes & A & B & G \\
\hline Maximum Load $(\mathrm{kN})$ & 31.415 & 33.524 & 35.380 \\
\hline Splitting Tensile Strength $(\mathrm{MPa})$ & 3.017 & 3.333 & 3.429 \\
\hline
\end{tabular}

Table 8. Freeze-thaw Splitting Test Results of Mixture Prepared by Three Mixing Processes.

\begin{tabular}{|c|c|c|c|}
\hline Mixing Processes & A & B & G \\
\hline Splitting Strength without Freezing and Thawing (MPa) & 0.96 & 1.02 & 0.91 \\
\hline Splitting Strength with Freezing and Thawing (MPa) & 0.79 & 0.93 & 0.87 \\
\hline TSR (\%) & 82.44 & 91.57 & 95.76 \\
\hline
\end{tabular}

As seen from Table 6, 7 and 8, the high temperature performance of the process $G$ is the best, the low temperature performance of the $\mathrm{G}$ process is the best, the process $\mathrm{B}$ is the second one. And that the water stability of process $\mathrm{G}$ is the best, followed by the process $\mathrm{B}$.

It concludes that mixing process will make Buton rock asphalt modified asphalt mixture road performance have a certain impact. Both B and $\mathrm{G}$ methods are greatly improved the performance, while in the conventional A method the mixture performance index in all three kinds of mixing process perform the lowest.

\section{Summary}

The mixing process of modified asphalt mixture of Buton rock asphalt were studied in this paper, the main conclusions are as follows:

(1) The mixing process of $B$ and $G$ the resulting mixture phase compared with the routine of preparation process a more conducive to dense, priority ranking for $B>G>A$, and the rest of the mixing process of void ratio difference is not obvious, and against Buton rock asphalt change of $70 \#$ base asphalt and SBS modified asphalt can be produced similar results. 
(2) Under the same air voids and the Buton rock asphalt modified matrix asphalt 70\#. The mixing process of $\mathrm{B}$ and $\mathrm{G}$ and conventional process from a mixture of high temperature, low temperature and water stability performance comparison, performance of conventional Process $\mathrm{A}$ is inferior to the other two, a priority rank for $\mathrm{G}>\mathrm{B}>\mathrm{A}$.

(3) By a comprehensive comparison of mixing process $\mathrm{B}$ and $\mathrm{G}$, although $\mathrm{B}$ mixture performance not good as $\mathrm{G}$, Although the mixing process of $\mathrm{G}$ obtained mixture performance best, but the in the same stone than inferior to the mixing process $\mathrm{B}$ easy to compaction, and the preparation procedure complex, but still better than the conventional preparation Process A, and it is the most conducive to dense, mixing process is easy operation of practical production, therefore, the use of mixing process $\mathrm{B}$ is recommended.

\section{Acknowledgement}

This research was financially supported by the Science and Technology Commission of Shanghai Municipality. "Research and demonstration on the complete set technology of ecological road with sponge city idea" (project number: 16DZ1202000)

\section{References}

[1] Cao Yadong, Yan Jun, Cao Zuguang, et al. Study on performances and applications of natural BMA bitumen [J]. Shanghai Construction Science and Technology, 2005(01): 53-55.(in Chinese)

[2] Xie Meidong, Li Xiangxiong. Experimental research on performance and modification mechanism of natural rock modified asphalt [J]. Hunan Communication Science and Technology, 2007, 33(3): 1-3. (in Chinese)

[3] Wang Gang, Liu Liping, Sun Lijun. Research on performance of modified asphalt with domestic natural rock asphalt and the mixture [J]. Highway Engineering, 2011(04): 72-75. (in Chinese)

[4] Zhong Ke. Research on the performance of Gilsonite [D]. Beijing: Research Institute of Highway, Ministry of Communication P.R.C, 2006. (in Chinese)

[5] Huang Wentong, Xu Guoyuan. Experimental investigation into pavement performance of Buton Rock Asphalt mixtures [J]. Journal of South China University of Technology (Natural Science Edition), 2012(02): 87-91. (in Chinese)

[6] The proportion desigh of Butonite Mastic Asphalt modified asphalt concrete [J]. Journal of Shangdong Jiaotong University, 2005(02): 35-38. (in Chinese)

[7] Research Institute of Highway, Ministry of Communication P.R.C. Technical Specifications for construction of highway asphalt pavements: JTG F40-2004[S]. Beijing: China Communications Press, 2005. (in Chinese)

[8] Research Institute of Highway, Ministry of Communication P.R.C. Standard test methods of bitumen and bituminous mixtures for highway engineering: JTG E20-2011[S]. Beijing: China Communications Press, 2011. (in Chinese) 